A useful addition would have been a separate glossary for the numerous abbreviations used in the text. Policy on how they were to be introduced was undecided; in two chapters they are collected in a footnote on the first page, while in the rest they pop in and out of brackets. There are more than 1,700 references, and excellent author- and subjectindexes enhance its value to the practising biochemist while for the serious microbiologist in any field it provides the perfect reference book into which he will find himself continually delving in search of the fundamental explanation of his observations.

L. B. Quesnel

\section{NON-LINEAR CONTROL SYSTEMS}

\section{Stability in Nonlinear Control Systems}

By Alexander M. Letov. Translated from the Russian by J. George Adashko. Pp. 316. (Princeton, N.J. : Princeton University Press; London: Oxford University Press, 1961.) 68s. net.

D HE Russian school of mathematical engineers is noted for the detailed and painstaking approach which it has made to many of the problems of control theory. This approach, and the use made of it in the U.S.S.R., differs markedly from the semi-empirical method which is customary in Britain and was, until quite recently, superior even to the American attitude to design.

In recent years translation of Russian papers and books have acted as a spur to Western engineering education and each new one is anxiously scanned to see if, to put it crudely, we have missed something !

One of the more significant of the recent translations for engineers is Popov's monumental Dynamics of Automatic Control Systems. This starts with the most elementary assumptions, both of previous knowledge of control systems and of the mathematical methods needed to discuss them, and is well suited to the needs of engineers trained in the British tradition.

Letov's book, dealing as it does with non-linear problems, is of a quite different kind. Naturally, a discussion of such material could scarcely be element ary, although some of the presentations given by Lefschetz and particularly by Cartwright, have at least the merit of being 'interesting enough' to encourage the reader to make the necessary effort. But the austere axiomatic and analytical approach of Letov makes the text one of the most difficult that I have encountered. To be fair it must be said that the formal mathematics needed to understand the book is quite limited: the difficulty lies, however, in the author's failure to relate his equations to the physical realities beloved of the engineer. There is scarcely a single 'number' in the book and no graph or diagram which is thought worthy of a scale or even a caption, a state of affairs which makes puzzling the remark, on the dust-jacket, that "-it does not hesitate to go into abundant details of computation. ...'

These criticisms should make it clear to readers of this review that the book is of far more use to mathematicians than to engineers. There are comprehensive discussions of Lyapunov's direct method for investigating stability, Hurwitz's theorem and Lure's transformations. The reduction of the equations of control systems to various Canonical forms is illustrated by reference to the problem of the
'Isodrome' regulator and, after discussing the stability of unsteady motion, the author examines the effects of velocity feedback and thus leads finally to an examination of the theory of the stability of the bicycle. Lest this everyday conclusion should raise hope of practical results it should be mentioned that the book ends with an analytical expression from which the reader is invited to decide the point for himself !

A. D. Воотн

\section{ANIMALS OF BRITAIN}

Animals of Britain

No. 1. Badgers. By Dr. Ernest. G. Neal. No. 2: Horseshoe Bats. By John Hooper. No. 3: Hedgehogs. By Maxwell Knight. No. 4: Water Voles. By Stéphanie Roden Ryder. No. 5: Grey Squirrels. By Monica Shorten. No. 6: Red Squirrels. By Monica Shorten. No. 7: Grey Seals. By H. R. Hewer. No. 8: Otters. By E. G. Neal.

Each number: Pp. 24. (London : Sunday Times Publications, Ltd., 1962.) 3s. $6 d$.

HE Sunday Times Publications, Ltd., is producing a series of booklets called Animals of Britain. Altogether there will be about twenty-six booklets, each dealing with one animal (with the exception of bats, when eleven different species will be divided between four booklets). So far, eight booklets have been published; another eight will appear in the autumn, and the remainder at intervals thereafter. The series is edited by Dr. L. Harrison Matthews.

Those already available are Badgers, by E. G. Neal ; Horseshoe Bats, by John Hooper; Hedgehogs, by Maxwell Knight; Water Voles, by S. R. Ryder; Grey Squirrels, by Monica Shorten; Red Squirrels, also by Monica Shorten; Grey Seals, by H. R. Hewer; and Otters, by E. G. Neal. It can be seen that many well-known naturalists appear among the authors.

Each booklet contains twenty-four pages. These are filled with a large number of black-and-white photographs, some informative diagrams and a detailed, though uncomplicated, text. Many of the photographs are unusual shots, including those of very young creatures and some, as yet, unborn. The diagrams are of such things as the layout of a badger's sett, the distribution of an animal, or comparisons. Except in Booklet No. 2, Horseshoe Bats, the text is subdivided under such headings as general appearance, distribution, habitat, food and feeding habits, the senses, breeding cycle, enemies, peculiarities, and general habits. This makes the text very easy to follow. In both Hedgehogs and Red Squirrels there is a section on legends. Badgers, Grey Squirrels and Water Voles contain sections suggesting how best to watch these animals. Hedgehogs as pets is another short section. Each booklet is concluded with a short list of books for further reading, and a full-page diagram of the skeleton of the animal.

The front cover of each booklet is attractive, with a colour photograph. The price is very reasonable, considering the information contained and the good presentation. Many adults will be interested to have all the details put beforc them in such a straight. forward manner, and it will be an excellent and reliable series for schools to have in their libraries. Young naturalists are sure to be waiting in eager anticipation for the rest of the series to be published. B. J. G. Martland 